1997

\title{
Freedom of Expression and Choice of Language
}

Leslie Green

Osgoode Hall Law School of York University

\section{Source Publication:}

Ethical Issues: Perspectives for Canadians, 2nd Edition. Peterborough, ON: Broadview Press, 1997.

Follow this and additional works at: https://digitalcommons.osgoode.yorku.ca/scholarly_works

Part of the Civil Rights and Discrimination Commons

\section{Recommended Citation}

Green, Leslie. "Freedom of Expression and Choice of Language." Ethical Issues: Perspectives for Canadians, 2nd Edition. Peterborough, ON: Broadview Press, 1997.

This Book Chapter is brought to you for free and open access by the Faculty Scholarship at Osgoode Digital Commons. It has been accepted for inclusion in Articles \& Book Chapters by an authorized administrator of Osgoode Digital Commons. 


\title{
Freedom of Expression and Choice of Language
}

\author{
LESLIE GREEN
}

This paper argues that sound principles of freedom of expression protect an individual's choice of which language to speak. They do so, not to guarantee against mistranslation, but rather to ensure that speakers are able to reach their intended audiences and, more importantly, to allow for the expressive value of speaking a particular language as a symbol of ethnic or political identification. The example of Quebec's Charter of the French Language and the resulting litigation is considered in some detail.

\section{THE PROBLEM}

In linguistically divided countries, governments often regulate the use of language: they make some languages official, they restrict others, they impose linguistic requirements on educational or professional qualifications, and so on. My question is this: Do sound principles of free expression direct or constrain such regulation?

The issue is a familiar one to Canadians whose federal government requires the use of French and English for certain

\footnotetext{
${ }^{*}$ Versions of this paper were read to a conference on freedom of expression at McMaster University, Hamilton, Ontario, and at the Boalt Hall School of Law, University of California, Berkeley. I am grateful to the participants, and to the editors and referees of this journal for helpful criticism.
} 
purposes, and whose provincial governments have often restricted one or the other. Historically, French and languages other than English bore the brunt of deliberate repression, but nationalist governments in Quebec have recently turned the tables and banned, in certain contexts, the use of English and other languages. Quebec's Charter of the French Language, for example, made French the sole official language of that province, and prohibited non- French commercial publicity, firm names and, with certain exceptions, public signs. ${ }^{1}$

In a series of important and highly controversial judgments, the Supreme Court of Canada struck down some of these provisions as inconsistent with the guarantees of free expression found both in the entrenched Canadian Charter of Rights and Freedoms and also in Quebec's provincial human rights statute. These decisions were generally admired by English Canadians and, not surprisingly, deplored by the Quebec French. In consequence, the government of Quebec used its power under the Charter to derogate from the free expression guarantees, a decision that they may, in retrospect, have regretted. That action quickly polarized public sentiment and was among the factors making it impossible for Quebec to secure the agreement of all the majority-anglophone provinces on constitutional amendments which would have given it more control 
over its cultural affairs. Perhaps the linguistic division of opinion on the cases was to be expected. More surpris- ing, however, was the political division, for the decisions did not attract much support from liberal and left-wing academics either. They were dis- appointed to see the Court protecting commercial expression and to see it assisting a historically powerful group (English Quebeckers) against a historically weaker one (French Quebeckers). Groups who are normally friends of free expression were thus surprisingly hostile to the Supreme Court's defense of it in these cases.

Part of the puzzle is explained by the fact that these cases involved commercial signs and that there are many liberals whose commitment to free expression does not reach that far. But it is, I think, quite wrong to let one's views about commercial expression occlude the broader issue here. First, some of the grounds on which Quebec defended its legislation (for instance, that its government enjoyed "democratic legitimacy," i.e. was elected) would permit the restriction of non-commercial expression as well. Second, some Quebec nationalists thought - and still think - that the impugned legislation did not go far enough in restricting English. Finally, the will to regulate more broadly was in any case manifest in the proposal of the Montreal Catholic School 
Commission to ban languages other than French from the playgrounds and corridors of their schools. None of this is resolved by one's views about commercial expression, so by focusing solely on that aspect liberals lost the opportunity to test their views more fully.

Still, it is not obvious that a sound view of free expression should protect choice of language. (And here I mean morally, and not just legally, sound.) Indeed, some Canadians regard that suggestion as a kind of legalistic joke, rather as if one argued that the Oleomargarine Act, in requiring margarine to be dyed orange, wrongfully discriminates on grounds of color. But I want to suggest that this is mistaken and that free expression does properly extend so far as to protect choice of language.

Principles of free expression protect expressive acts by imposing dis- abilities or duties on people, and they do so in order to protect such acts. The question whether freedom of expression protects choice of language thus needs to be distinguished from a broader question: Are there any principles of political morality that direct or constrain the regulation of language?

The questions are importantly different. Governments should not, for instance, act irrationally. Since there is no evidence that 
Quebec's restrictions on external commercial signs would do more good than harm that is enough to impugn them, at least morally and perhaps constitutionally as well. But that is not an argument from free expression. Likewise, it is wrong to pay English-speaking workers more than French-speaking workers when language is irrelevant to the job. But the wrong is one of discrimination, not the violation of freedom of expression. Again, it would be wrong to punish people for speaking French at home. But the evil here is just that in prohibiting a harmless activity it restricts their personal liberty.

Principles of rationality, non-discrimination, and personal liberty will in such ways often protect language use indirectly, as fallout from their central aims. Free expression plays an independent role only if it enhances these protections, if it protects language beyond what can be expected from other principles of political morality (Greenawalt, 1989: 9-10). That is the sort of principle I want to explore here.

I follow Scanlon in regarding an expressive act as "any act that is intended by its agent to communicate to one or more persons some proposition or attitude" (Scanlon, 1972: 206). Expressive acts are thus all those that bear the communicative intentions of some agent, whom for sake of 
simplicity we shall call the speaker. This must not, however, be taken to imply that all expressive acts are speech acts: writing, signalling, playing music, painting etc. can all be expressive, as can some criminal acts, including acts of terrorism and civil disobedience. Much fruitless debate in political theory is inspired by the narrow language of the First Amendment to the American Constitution which protects "freedom of speech, or of the press...." This has given rise to many unedifying attempts to distinguish speech and action. In contrast, section 2 of the Canadian Charter, like many other human rights documents, casts the net more broadly to catch: "freedom of thought, belief, opinion and expression, including freedom of press and other media of communication" (Canadian Charter, 1982). That is, I think, a better way to demarcate the territory. Such unity as exists in the area flows, not from the fact that these are all in some obscure sense forms of "speech," but rather that they are all expressive.

Generally, an act counts as expressive only if it attempts to get others to understand or share some proposition or attitude, and only if it does this communicatively, that is, by trying to get them to recognize that it is done with that intention. ${ }^{2}$ I say, 
"proposition or atttitude," because it would be a poor and excessively rationalistic view of human communication to think that it only serves the communication of truths. The contents of communicative acts are quite diverse: we attempt to communicate to others, not only propositions or ideas to be believed, but attitudes and values to be shared. In the case of artistic expression, for example, communicative intent is hardly ever propositional. Attitudes, values, and dispositions all enter into our common life in important ways and are transmitted in part through their expression. In any case, so far as the Charter is concerned, the cognitive and the affective are both accommodated by the language itself which distinguishes the terms "thought," "belief " and "opinion" from the more general notion of "expression."

The reasons for protecting such acts are, I believe, several and are grounded in the interests of speakers, of their audiences, and of the general public. Attempts to reduce these intersecting and sometimes competing considerations to a monistic theory have not met with great success, ${ }^{3}$ for a cluster of different kinds of interests is at stake here. Surely consequentialist considerations, such as J.S. Mill's claim that free expression promotes knowledge of the truth, have weight 
(Mill, 1962: chap. 2). At the same time, it fosters and expresses both collective and individual autonomy: it serves democratic decision making, artistic and cultural endeavor, the expression of individual identity, and so on. Interestingly, the Supreme Court of Canada has explicitly endorsed such a pluralistic account of the grounds of free expression (Irwin Toy at 97677; Ford at 712) and that is the view I shall adopt here.

I do want to reiterate, however, that the interests at stake in free expression are not, on this view, just individual ones. They have an important social dimension, recognition of which is, contrary to the allegations of some theorists, deeply rooted in the liberal tradition. Mill, for example, held that: "Were an opinion a personal possession of no value except to the owner; if to be obstructed in the enjoyment of it were simply a private injury, it would make some difference whether the injury was inflicted only on a few persons or on many" (Mill, 1962: 142). But, he continued, the restriction of opinion harms not just the individual but the public interest, and it is not just for the sake of a single speaker that we protect expression. To prevent even one person from speaking is wrong, not mainly because of the value of this liberty to her or to him, but because of the contribution it makes to the common good. 
Meiklejohn took the public interest justification even further, denying the speaker's interest any independent moral importance at all: "What is essential is not that everyone should speak, but that everything worth saying shall be said" (Meiklejohn, 1960: 26). Of Course, principles of free expression do not require that everyone should speak; at most they require that everyone has the opportunity to speak or remain silent. And the connection between what is worth saying and what is worth protecting is more complex than Meiklejohn allows. We do not want to claim that a speaker's interest in uttering a banal, commonplace ideal should count for little merely on the ground that, having been said before, its contribution to the public interest is slight. Indeed, a single-minded concern that, as Meiklejohn puts it, "everything worth saying shall be said," could easily lead to the violation of what we normally think of as paradigm rights of free expression. We do not believe that only those things worth saying should be permitted to be said nor even that scarce resources should be apportioned among speakers according to how socially valuable their views are. Moreover, in some cases we do regard it as important that everyone has an opportunity to speak, 
even if that means that the amount of time devoted to the worthless and the worthwhile is about the same. Meiklejohn thought his argument a democratic one, but the notion that everyone should speak in fact has deep roots in democratic theory, beginning with the classical Greek notion of isogoria. While the public interest is essential to understanding the full importance of freedom of expression, there is also an individual interest that cannot be discounted.

\section{MEDIUM AND MESSAGE}

There is an objection, however, to thinking that choice of language should be protected by such principles. They protect expressive acts in virtue of their expressive character; but not all features of such acts are expressive. For example, it is commonly thought that free expression does not protect the time, manner, or place of expression. Thus the regulation of radio frequencies, or the quality and supply of paper during war time, or the chemical additives present in artists' paints and materials, may all have effects on the character and quality of expressive acts, and 
may at the margin even inhibit some forms of expression and promote others. But, according to the proposed distinction they would count as regulation of the media of communication only and not of the message itself. These normally bear, the argument goes, on the form rather than content of expression. Likewise, it may be said, whether the medium of expression is French, English or Cree, the message remains invariant, so restrictions of medium need not offend principles of free expression.

That was how one Canadian court saw the issue. In Irwin Toy, a case testing the constitutionality of legislation restricting advertising directed at children, Hugessen, A.C.J. introduced a distinction which was to prove pivotal. He said, "The late Dr McLuhan notwithstanding, message and medium are, in law, two very different things" (Irwin Toy at 58). He held that a legislature which regulates or restricts the medium in which some message is communicated is not regulating or restricting the message itself and thus cannot be said to be regulating or restricting any expressive act.

This reasoning also dominates the trial judgment in Devine which, though overturned on appeal, nicely puts the objection we now consider. Dugas, J. applied the distinction between medium and message to the case of language: "Language, after 
all, is nothing more than a code of written or oral signs, used by those who know it to communicate with each other" (Devine at 375). Prohibiting the use of a particular code, he stated, does not therefore interfere with the communicative intention, for any other code might be used to express the same propositions or attitudes. Hence "Freedom of expression does not include the freedom to choose the language of expression" (Devine at 379).

There are many interesting and important aspects of these judgments that we need not consider here. What I do want to focus on is the central distinction between medium and message and the use to which it was put. The reasoning seems to have gone something like this:

1. Only expressive acts are candidates for the protection of freedom of expression;

2. A language is nothing more than a content-neutral code;

3. Thus, restricting the choice of language cannot restrict any expressive act.

Now I have already endorsed (1) and suggested some of the reasons one might have for protecting such acts, so let us turn to (2). The word "code" which I draw from the judgment is 
unhappy, suggesting as it does an artificial medium used in place of a natural language. The fact that the same meaning may be borne by a sentence spoken in English and the same English sentence sent over the wire in Morse code would hardly suffice to establish the semantic equivalence of that sentence and its best French translation. There are codes and then there are "codes." We must take care not to become enchanted with the jargon of some fashionable linguistic theory. The sense in (2) just amounts to this: it is roughly true that anything that can be said in English can also be said in French. But, as we shall see below, the fact that this is only roughly true allowed the Supreme Court of Canada in Ford to reject (2) and the inference drawn from it. That result was not too surprising, for there were plenty of other clouds on the horizon for this distinction, at least as a matter of law.

First, medium of communication is expressly mentioned in the Charter as being included in the guarantees of section 2 . It is true that, in that context, the central cases of such media are the press and airwaves, but neither the language of the constitution nor the decided cases inhibits its development by analogy. Even if medium is distinct from message, in at least some cases the Canadian constitution finds reasons for protecting both.

Second, the following words of an earlier Supreme Court 
judgment suggest a view of language as something more than a content-neutral code:

The importance of language rights is grounded in the essential role that language plays in human existence, development and dignity. It is through language that we are able to form concepts; to structure and order the world around us. Language bridges the gap between isolation and community, allowing human beings to delineate the rights and duties they hold in respect of one another, and thus to live in society. (Reference re: Manitoba Language Rights at 19)

Finally, and perhaps most important for present purposes, this view of language seemed inconsistent with the very statute the trial judge was attempting to interpret. For its preamble opens with the ringing declaration that "the French language ... is the instrument by which that people [i.e. Quebeckers] has articulated its identity" (Charter of the French Language, 1977). As Boudreault, J. shrewdly observed in the trial judgment in Ford, this makes it very difficult to suppose that the legislators conceived of language merely as a neutral code and thus that they intended that the Act should regulate its use only in that respect 
(Ford at 724).

So in deciding as it did, the Supreme Court certainly had a reasonable footing: nothing in Canadian law prohibited their finding that freedom of expression includes the freedom to choose one's language and there was enough directing them along that path. But was it, in the end, a wise decision? Can it be defended in principle? I turn now to examine three arguments to that conclusion.

\section{A SEMANTIC ARGUMENT}

One of the arguments the Supreme Court accepted, and one that has an obvious appeal, is to deny the premise of the objection. If it is wrong to think of a natural language as a content-neutral code, then it is wrong to think that regulating the code is not regulating content. Thus, in Ford the Court unanimously rejected (2) in the following words:

Language is so intimately related to the form and content of expression that there cannot be true freedom of expression by means of language if one is prohibited from using the language of one's choice. Language is not merely a means 
or medium of expression; it colors the content and meaning of expression. ${ }^{4}$ (Ford at 748$)$

The Court thus exploits the inevitable haziness of the boundary between medium and message. That what can be said in French can also be said in English is only roughly true because choice of language colors the content and meaning of expression. Language is not, therefore, a content-neutral code.

Was the Court right about that? It is true that the expressive power of language varies, and that exact synonymy may be unavailable in some cases. Considering cultural resonance and sonorities, it would be hard to say that there are no semantic differences between the roughly equivalent idioms, 'filer $a$ l'anglais" and "to take French leave." Language does in such cases color the meaning of the expression.

But is this sufficiently important and pervasive to bring choice of language under the comprehensive protection of free expression? I do not think so. Valerie Ford's offense, after all, was to have displayed the word "wool" alongside "laine" in the window of her wool shop. It is surely not to secure against any possible semantic slippage that we would defend her right to freedom of expression. This is not to deny that such slippage can occur, even in the context of commercial signs. A "depanneur" 
is not exactly a "convenience store." The differences in meaning are real; but they are occasional and do not matter much. If we are about to impose duties and disabilities on people as a matter of general policy we must make sure that the stakes are high enough to warrant it. To show that language does in some cases flavor the meaning of expression will not warrant adopting a general policy of protecting choice of language just in order to catch such cases of heteronymy. The availability of circumlocutions, or the adoption of some foreign words and terms, would be a satisfactory alternative.

For this reason the tempting analogy with obscenity is misguided. One might initially be inclined to regard choice of natural language as being on a par with choice of tone or force and, reasoning along the lines of the U.S. Supreme Court in Cohen v. California, argue that to restrict language is to restrict a whole mode of communication. But to exclude obscene or vulgar speech from the protections of free expression is to remove a distinctive tool, one which might prove useful or even necessary in circumstances that cannot easily be isolated in advance ${ }^{5}$. The potential heteronymy of French and English near-equivalents is neither as pervasive nor as unidirectional as the power of vulgar speech, so the analogy is unhelpful. There just isn't a general 
linguistic tone or pragmatic effect that accrues to speaking English in the way that one might be thought to accrue to speaking vulgarly. So while it is certainly true as a descriptive matter that semantic slippage occurs, it is hard to endorse the normative thesis that this is what ought to bring choice of language under the protective umbrella of free expression.

\section{AN INSTRUMENTAL ARGUMENT}

A better route to the protection of choice of language is surely the instrumental one. Restricting the use of certain languages simply cuts off potential audiences or makes it more difficult to reach them, and that harms one of the core interests underlying freedom of expression on any plausible account.

To take a clear example: suppose a government restricted the language in which political commentary might appear in the newspapers, requiring that all published criticism of its policies be in Ojibway, while favorable comment could be in any language. What matters here is not the possible semantic slippage, but the closing down of channels of communication by restricting both speakers and their potential audiences. 
Now this argument bears, one must concede, less heavily on requirements than on prohibitions. Canada's Official Languages Act of 1969, for example, requires various officials and government agencies to use both French and English, and Quebec's Charter of the French Language makes wide use of such requirements in order to promote the use of French in the working world. And they do so partly for instrumental reasons that are ultimately based on audience interests. The Charter of the French Language, for example, seeks to establish French as the normal working language of commerce and government in Quebec thereby directly protecting the substantial interest that the francophone majority has in being able to understand communications of all sorts. It is important to note, moreover, that the audience interest is not exhausted by the immediate benefits of intelligible communication. It is well-known that patterns of language use will also have substantial secondary effects on people's life chances, including their opportunities for education, occupational advancement, and social and geographic mobility.

Now, in the case of intended audiences, speakers will generally aim to communicate in a language that the audience understands. We should not, however, assume on that basis that everyone's interests can be best served without any regulation of 
language at all. The free market can fail in language as it can elsewhere. When the audience is linguistically fragmented there may be complex problems of coordination involved in finding a common language. When minorities are bi- or multilingual there is the potential for collective action problems in sustaining the use of minority languages, and there is the risk of majorities oppressing linguistic minorities. Nonetheless, it is easy to see why speakers have an interest in the freedom to use the language that they feel is best suited to their audiences. Unintended audiences also have an interest in the intelligibility of communication, however. It matters not only what others say to you, but what is being said generally. Since speakers have weaker, and in some cases no, incentives to serve the needs of unintended audiences, this may provide another reason for required use.

Might one argue that forcing someone to use a language other than the one he or she would otherwise use in that context limits the speaker's choice of medium and therefore must, at the very least, call for a persuasive justification? To assess this claim, one must investigate more closely the structure of speaker's interest. In part, it derives from the intended audience's interest in intelligible communication: the intention to reach them is 
frustrated if one cannot do so. But we are not now considering a case in which the speaker's audience is limited by prohibition, but only a case in which the potential audience is expanded. A requirement that commercial signs and publicity be in French as well as another language, for example, does not inhibit the speaker's capacity to communicate with the audience at which the signs are directed. Could a speaker wish that a certain audience not receive a particular communication? No doubt, although plausible cases will turn, not on freedom of expression, but on the right to privacy.

The instrumental argument for protection for choice of language is thus an important one, though it may fail in some circumstances. Widespread individual bilingualism, or even the availability of convenient translation, lessens its force. A more discriminating policy of protecting choice of language where it is necessary for effective communication might answer to the same concerns and have fewer costs. And over time languages can be learned, so the need to do so stimulates investment in language learning. Quebec's language regime weighs less heavily on the anglophone community now than it would have done twenty years ago. Such are the limitations on the instrumental argument, so it seems unlikely that general protection for choice of language 
could be completely defended on instrumental grounds alone.

\section{AN EXPRESSIVE ARGUMENT}

There is, however, a third and independent reply to the objection that language is merely a non-expressive medium of communication, one noticed though not much elaborated by the Supreme Court. Choice of language should be protected because it is an expression of identity and individuality:

It is, as the preamble of the Charter of the French Language itself indicates, a means by which a people may express its cultural identity. It is also the means by which the individual may express his or her personal identity and sense of individuality. (Devine at 375)

This is an aspect of the romantic, as opposed to rationalist, tradition in free expression. Its context is not the forum or marketplace of ideas, but rather the organic relations between an individual and his or her community. I say this is an independent objection, for it may succeed even where the instrumental argument fails, and even when the thesis of content-neutrality holds. Returning now to the argument set out in section 2, above, we can see a further mistake. The thesis of content-neutrality does 
not show that a natural language is "nothing more than a code." Compare the following inference:

4. A flag is a piece of cloth,

5. Therefore, a flag is nothing more than a piece of cloth.

The conclusion does not follow because a flag can be both a piece of cloth and something more than a piece of cloth. Likewise, a language can be a content-neutral code and something more than a content-neutral code. If the something more makes it expressive, then the fact that it may also appropriately be described as a neutral code cannot change that.

To be still more precise, we do not even need to show that language is something more than a neutral code in order to justify the protection we want to accord it. Even if it were true that a natural language is nothing but a neutral code, and even if restrictions on language would not restrict the potential audience, the argument given above would still be invalid. For consider:

6. Choice of language is a candidate for protection of free expression only if it is an expressive act;

7. Language is nothing more than a neutral code;

8. So, freedom of expression does not include freedom to choose language of expression. 
Even if (7) were true, (8) would still not follow, for (8) is about choice of language, and not about language itself. The error thus lies not just in the arguable falsehood of (7), but in an equivocation between "language" as an abstract entity and "choice of language" as an act. Invoking again our earlier analogy, we might compare:

9. Waving a flag is a candidate for protection of free expression only if it is an expressive act;

10. A flag is nothing more than a piece of cloth;

11. So, freedom of expression does not include freedom to wave a flag.

Here, the fallacy is patent, for the supposed truth of (10) plainly has nothing whatever to do with (11). A flag, like a language, is not an act of any kind, let alone an expressive one. But speaking a particular language, like waving a flag, is indeed an act and very possibly expressive. Thus, the purported distinction between medium and message is irrelevant. The fact, if it be one, that medium and message are two different things does not even begin to show that choice of medium cannot be intended to convey a message. 
It is important to distinguish between the expressive argument defended here and the semantic argument that I rejected above. Suppose it were permitted to say "Long live a free Quebec!" but prohibited to say "Vive le Quebec fibre!" What is most significant: the fact that there are nuances of meaning, historical and cultural resonances, poetics of sound present in "Vive" but absent from "long live"? I doubt it. The significance of choice of language here lies not in what it says but in what it shows. Saying it in French is a doubly political act, for the propositional content is backed up by the fact that the utterance displays the legitimacy of the language and its relation to nationhood.

The argument we are pursuing is a normative one, but it does depend on certain social facts. It fails unless it actually is the case that language use has a social or individual meaning. This cannot be established a priori. But at least in Canada there is plenty of evidence that in many contexts it does. As I said earlier, the expressive function of language was not missed even by the legislators. The Charter of the French Language begins, "Whereas the French language, the distinctive language of a people that is in the majority French-speaking, is the instrument by which that people has articulated its identity. 
..."6 What is distinctively nationalistic here is merely the suggestion that a group of people who are only "in the majority" francophone constitute "a people." The reality in a pluralistic society is that language choice permits each people to express its identity. The way this is done is largely a social creation, governed by convention, context and history. ${ }^{7}$ In Canada, choice of language bears a number of meanings, of which ethnic identification and political affirmation are the most important.

Those who choose to use a particular language often thereby signal their sense of identification with an ethnic or cultural group. This is most commonly true of minority language speakers in circumstances where use of their language imposes some social or economic cost. The language establishes a link with an intended audience, a link which simultaneously invokes a boundary between those inside and those outside the group. This mark of distinction is often a source of value to minority language speakers, and legitimately so. Notice that ethnic identification may be expressed even by those who are monolingual minority-language speakers. The notion of "choice" in play may well be an attenuated one. For language use to have the expressive character I have attributed to it, it is not 
necessary that a person deliberately use one language and avoid another in circumstances where options are available. The expressive act need not be, for example, speaking Italian instead of English, but simply speaking Italian instead of remaining silent or allowing others to speak on one's behalf.

Language may also be an expression of political identity. Quebec's policies of francisation express not only a boundarydefining sense of common feeling, but also a political position which celebrates the distinctiveness of Quebec society and its aspirations for autonomy. It is no accident that minority language use is often a political marker, and not surprising that suppression of such languages is often undertaken with political aims in mind. The various forms of compulsion to which Estonian, Croatian, or Welsh speakers have been subject by their governments was motivated by a desire to suppress social formations which embody and promote nationalist politics. ${ }^{8}$ That repression was unjust, but it was not ill-informed: use of those languages was indeed a political act.

Here again, the consequences of requiring the use of a certain language are likely to differ from those of prohibiting the use of others. The decision not to use a particular language may in some circumstances be expressive: it may be an act of resistance. In 
other cases, it may be understood that to use a particular language is not necessarily to identify with the ethnic group whose language it characteristically is, nor to endorse any political view. A language may simply be, and be understood to be, a lingua franca. More- over, the burden of required use may be partly alleviated by the division of labor. Organizations like companies and bureaucracies may have the power to arrange their affairs so that, for example, only those willing to use English must do so. And where the regulations apply directly to individuals, they often do so only for limited contexts and purposes. This is not to deny that required use is ever onerous. When language has become politically charged with the burden of nationality, use of language is almost inevitably an expressive act. Both prohibitions and requirements on use limit that expression, though generally in different degrees.

Unlike the semantic thesis, the expressive thesis is pervasive: the use of a language may have an expressive function without regard to subject matter. The sign in Valerie Ford's shop had a social and political significance quite apart from its semantic content. Indeed, Quebec nationalists have often correctly noticed that the use of English by merchants is not purely a matter of commercial expediency but is in part a collective non placet, sometimes even a 
political provocation. To denounce it in one breath and then in the next defend prohibitions on English on the ground that they merely regulate a neutral code is either blindness or hypocrisy.

Since this expressive character may break out at any point, even on a commercial sign, there seems to be no way one might adopt narrower protections to serve the same ends. Unlike the instrumental argument, the expressive argument is capable of supporting broader principles. The strongest objection to this argument is rather different. It is that the interests at stake are not sufficiently weighty or general to warrant holding others dutybound to protect them or disabling them from infringing them. Is that a credible position? The power of ethnicity and nationality in organizing personal identity, the widely felt need for rootedness, and the structuring power of culture all suggest that identification with an ethnic group may be a substantial human good. Expressing such identification is good to the extent that it constitutes, reinforces and adapts it.

Perhaps one might object that these interests, though powerful, are purely private. A follower of Chafee, for example, might be tempted in that direction. He saw the underlying values of free expression to be these:

There is an individual interest, the need of men to 
express their opinions on matters vital to them if life is to be worth living, and a social interest in the attainment of truth, so that the country may not only adopt the wisest course of action but carry it out in the wisest way. (Chafee, 1964: 33)

Ignoring the social interest, Chafee thought, leads people systematically to underestimate the importance of free speech. But his view of what the social interest actually comprises is an implausibly narrow one. The expressive need is not merely individual, nor is the social interest merely that of attaining the truth. Sound public policy is to be guided, not merely by the true, but by the good. There is a common interest in a regime which enables and supports the expression and exploration of ethnic identities, at least when these help structure valuable forms of life. Not only is this good in itself, but it indirectly contributes to a climate of ethnic tolerance and to the public good of linguistic security, so that each may speak his or her mother tongue without unfair pressure to conform. The expressive interest is thus of general value and not what Mill called a "personal possession;" its violation is not merely a "private injury" (Mill, 1962).

It is here, I think, that one finds the deepest and most important roots of free expression and why, of the three arguments I have 
canvassed, the expressive one is so important in completing the

case for protecting choice of language.

LESLIE GREEN is an Associate Professor in the Department of Philosophy and at the Osgoode Hall Law School of York University, Toronto, where he is also Director of the Graduate Programme in Law. He is author of The Authority of the State, and co-editor of Law and the Community. He works mainly in legal and political theory, and also has research interests in the politics of language and culture.

\section{NOTES}

1. The Original Act, R.S.Q. 1977, c. C-11, provides that "Except as may be pro- vided under this act or the regulations of the Office de la langue franraise, signs and posters and commercial advertising shall be solely in the official [i.e. French] language." Similarly, s. 69 prohibits non-French firm names. Section 58 exempts publicity carried in publications circulating in languages other than French, and religious, political, ideological or humanitarian communications provided that they are not of commercial character (s. 59). Nor does it apply to small businesses of less than four employees, to publicity for the cultural activities of non-French ethnic groups, or to business specializing in foreign or ethnic goods.

2. The qualification is necessary because an act can try to get others to share a belief in some other way. If A wants B to think it is cold in the room, A can achieve this communicatively, e.g. by telling B that it is cold, or non-communicatively, e.g. by opening a window and making B cold. The second does not require for its success that B recognize $\mathrm{A}^{\prime}$ 's intention in opening the window, and thus is not a communicative act in the sense under discussion here.

3. Alexander Meiklejohn, for instance, thought that speech should be protected only when it can be reliably thought to promote selfgovernment. Thus it excludes commercial radio broadcasts: "The radio, as we now have it, is not cultivating those qualities of taste, of reasoned judgment, of integrity, of loyalty, of mutual understanding upon which the enterprise of self-government depends. On the contrary, it is a mighty force for breaking them down" (Meiklejohn, 1960: 87). What would he have thought of comic books, pop music, or television?

4. There is in fact a complication in the judgment, for while the above passage suggests that choice of language is protected because regulation of language is regulation of content, the Court also says that the reference in s. 2 to freedom of "thought," "belief," and "opinion" shows that the Charter's protections go beyond what it calls "mere content," or at least "content of 
expression in its narrow sense."

5. Cf. Kopyto per Corry, J.A., at 226: "Hyperbole and colourful, perhaps even disrespectful language, may be the necessary touchstone to fire the interest and imagination of the public to the need for reform, and to suggest the manner in which that reform may be achieved." Per Goodman, J.A., at 259: "The expression of an opinion which may be lawfully expressed in mild, polite, temperate, or scholarly language does not become unlawful because it is expressed in crude, vulgar, impolite, or acerbic words."

6. The equally authoritative French version reads: "Langue distinctive d'un peuple majoritairement francophone, la langue franraise permet au peuple quebecois d'exprimer son identite."

7. The context-dependence of meaning provides an illustration of the limits of abstract argument in political philosophy. One cannot resolve these issues solely by appeal to our concepts of 'expression,' 'language,' etc. It is no thesis of mine that choice of language is always, universally, or necessarily protected by principles of free expression. I am merely trying to identify cases in which it is. Does this need to attend to context suggest that language is ill-suited for protection by constitutionally entrenched rights? I make no claims about that here: the question turns on the nature of rights, and on moral and institutional arguments for putting certain matters beyond the reach of ordinary politics. The issues are well-known. But I might note one general point. One might object that, in view of the social character of our interests in language, it must be an inappro- priate matter for rights, for they only protect individuated interests. The objec- tion is too hasty, for it elides a number of interestingly different ways in which interests may fail to be fully individuated. For example, individuals may have rights to certain collective goods. See, Green (1991) and cf. Reaume (1988).

8. Political affirmation is often but not always coincident with ethnic identification. Some bilingual Canadians use their second official language in post offices or at border crossings in order to make a political statement without thereby intending to express any sense of ethnic identification with the other group.

9. The passage refers to the interests protected by the First Amendment to the American Constitution, but there is no evidence that Chafee thought that there were any important expressive interests not protected by that document.

\section{REFERENCES}

CHAFEE, ZECHARIAH (1964) Free Speech in the United States. Cambridge, MA: Harvard Univ. Press.

GREEN, LESLIE (1991) "Two Views of Collective Rights," Canadian Journal of Law and Jurisprudence 4: 315-27.

GREENAWALT, KENT (1989) Speech, Crime, and the Uses of Language. New York: 
Oxford Univ. Press.

MEIKLEJOHN, ALEXANDER (1960) Political Freedom: the Constitutional Powers of the People. New York: Oxford Univ. Press.

MILL, JOHN STUART (1962) Utilitarianism, On Liberty, Essay on Bentham edited by Mary Warnock. New York: New American Library. REAUME, DENISE (1988) "Individuals, Groups, and Rights to Public

Goods," Univer- sity of Toronto Law Journal 38: 1-28.

SCANLON, THOMAS (1972) "A Theory of Freedom of Expression," Philosophy and Public Affairs 1: 204-26.

\section{CASES CITED}

Cohen v. California (1971) 403 U.S. 15.

Devine c. P.O. Quebec et P.O. du Canada mis en cause (1982) C.S. 355 (Can.)

Ford v. A.G. Quebec (1984) 18 D.L.R. (4th) 711 (Can.)

Ford v. A.G. Quebec (1988) 2 S.C.R. 712 (Can.)

Irwin Toy Ltd. c. P.O. du Quebec et Gilles Moreau (1982)

C.S. 96 (Can.) Reference re: Manitoba Language Rights

(1985) 19 D.L.R. (4th) 1 (Can.) R. v. Kopyoto (1988) 47

D.L.R. (4th) 213 (Ont. C.A.) (Can.)

\section{STATUTES CITED}

CANADIAN CHARTER OF RIGHTS AND FREEDOMS s. 2(b), Part I of the CONSTITUTION

ACT OF 1982 being Schedule B of the CANADA ACT OF 1982 (U.K.), 1982, chap. 11.

CHARTER OF THE FRENCH LANGUAGE R.S.Q. 1977 c.C-11 (Can.)

OFFICIAL LANGUAGES ACT OF 1969 